\title{
A RETÓRICA DESPOLITIZANTE DA CORRUPÇÃO E A DIALÉTICA DA GRANDE E PEQUENA POLÍTICA: UMA NARRATIVA SOBRE O ESPETÁCULO NEOLIBERAL
}

\author{
LA RETÓRICA DESPOLITIZANTE DE LA CORRUPCIÓN Y LA DIALÉTICA \\ DE LA GRANDE Y PEQUEÑA POLÍTICA: UNA NARRATIVA SOBRE EL \\ ESPECTÁCULO NEOLIBERAL \\ THE DESPOLITIZING RHETORIC OF CORRUPTION AND THE DIALECTICS \\ OF THE GREAT AND SMALL POLITICS: A NARRATIVE ON THE NEOLIBERAL \\ SPECTACLE
}

\author{
Fernanda Abi-Chahin de Oliveira FERREIRA ${ }^{1}$
}

RESUMO: O objetivo deste artigo é abordar o caráter despolitizante da retórica da corrupção e como esta é um verdadeiro fenômeno da substancialização hegemônica da pequena política na realidade neoliberal brasileira. Sem perder de vista a categoria determinante das condições materiais e a concepção dialética da história, a hipótese que conjuga este estudo é de que, no neoliberalismo, o Capital soma esforços para estabelecer um afastamento entre os sujeitos e os temas da grande política e, para tanto, espetaculariza o terreno da pequena política. $\mathrm{O}$ presente artigo, desse modo, é guiado por importantes chaves gramscianas - como a hegemonia, a busca por consenso e a ideia de intelectual - ao tratar da realidade neoliberal, do espetáculo e da corrupção como retórica. Além disso, analisa-se como a lógica do Espetáculo, cunhada por Debord, dificulta a ação política, no contexto neoliberal, e corrobora para a aceitação de retóricas como a da própria corrupção.

PALAVRAS-CHAVE: Grande política. Pequena política. Espetáculo. Corrupção. Neoliberalismo.

RESUMEM: El objetivo de este artículo es abordar el carácter despolitizante de la retórica de la corrupción y cómo ésta es un verdadero fenómeno de la sustancialización hegemónica de la pequeña política en la realidad neoliberal brasileña. Sin perder de vista la categoría determinante de las condiciones materiales y la concepción dialéctica de la historia, la hipótesis que conjuga este estudio es que, en el neoliberalismo, el Capital suma esfuerzos para establecer un alejamiento entre los sujetos y los temas de la gran política y, para ello, espectaculariza el terreno de la pequeña política. El presente artículo, de este modo, es guiado por importantes claves gramscianas -como la hegemonía, la búsqueda por consenso y la idea de intelectual- al tratar de la realidad neoliberal, del espectáculo y de la corrupción como retórica. Además, se analiza cómo la lógica del Espectáculo, acuñada por Debord, dificulta la acción política, en el contexto neoliberal, y corrobora para la aceptación de retóricas como la de la propia corrupción.

${ }^{1}$ Universidade Federal do Estado do Rio de Janeiro (UNIRIO), Rio de Janeiro - RJ - Brasil. Bacharelado em Ciência Política. Em intercâmbio acadêmico, concluiu seus estudos de graduação na Université Paris Nanterre (Paris X). ORCID <http://orcid.org/0000-0002-4510-1441>. E-mail: nandadf@gmail.com 
PALABRAS CLAVE: Gran política. Pequeña política. Espectáculo. La corrupción. El neoliberalismo.

ABSTRACT: The aim of this article is to discuss the depoliticizing character of the rhetoric of corruption and how this is a true phenomenon of the hegemonic substantialization of small politics in Brazilian neoliberal reality. Without losing sight of the determinant category of material conditions and the dialectical conception of history, the hypothesis that conjugates this study is that, in neoliberalism, the Capital sums up efforts to establish a distance between the subjects and the themes of the great politics and, for that, it spectacularises the terrain of small politics. The present article is thus guided by important Gramscian keys - such as hegemony, the search for consensus and the idea of an intellectual - in dealing with neoliberal reality, spectacle and corruption as rhetoric. In addition, we analyze how the logic of the Spectacle, coined by Debord, hinders political action in the neoliberal context, and corroborates the acceptance of rhetoric such as corruption itself.

KEYWORDS: Great politics. Small politics. Spectacle. Corruption. Neoliberalism.

\section{Introdução}

Buscamos no presente artigo tratar da retórica despolitizante da corrupção analisada sob a perspectiva gramsciana de grande política e pequena política. E, diante dessa abordagem, discutimos neste estudo o projeto neoliberal como principal doutrina de espetacularização do terreno político. Para tanto, lançamos luz a determinadas chaves gramscianas como a ideia de consenso e de senso-comum, indispensáveis para fundamentação deste trabalho.

Nesse sentido, o processo de dominação que o Brasil enfrentou durante séculos ainda evidencia sequelas graves de sua formação social, o que corrobora para as agudas contradições internas.

O poder hegemônico não é legitimado apenas pela força bruta, isto é,pela violência direta, mas sobretudo pelo poder da fala e pela respectiva posição de detentores do conhecimento e verdade universal, que determinada classe assume ao longo da história.Tão logo, através de predicações que propõem uma visão linear da história, o que se observa é um definido objetivo de elaborar mecanismos e elementos que consigam conter, controlar e moldar uma sociedade culturalmente previsível. Afinal, gozar de controle sobre uma região 
com tantos recursos naturais e estratégicos, como o Brasil, é fundamental para o capitalimperialismo. $^{2}$

Nessa perspectiva, dividimos o artigo em cinco partes - a primeira sendo esta introdução. De modo que, na parte dois (2), procuramos identificar a realidade do espetáculo tendo como ponto de partida a retórica da corrupção como elemento cristalizador. Neste momento do artigo, o intuito central é demarcar o conceito de espetáculo, cunhado por Guy Debord, no contexto do neoliberalismo - levando em consideração, determinados traços e consequências importantes para o terreno político, como por exemplo, as subjetividades forjadas pelo sistema político-econômico a fim de minar a ação política e coletiva.

Em um terceiro momento, é abordado no ponto três (3), o tema da pequena e grande política e é aqui que caracterizamos os referidos conceitos gramscianos a fim de compreender a ideia de intelectual, senso-comum e consenso - basilares para este artigo.

Em seguida, incidimos no ponto quatro (4) sobre a ideia de consenso no contexto neoliberal e, em última instância, como se desdobra a construção deste consenso, de modo que em determinadas conjunturas, o que se observa é uma verdadeira política de choque, em detrimento do consenso. Por fim, no ponto cinco (5), reunimos os elementos finais para a conclusão deste artigo.

\section{A retórica da corrupção e a realidade espetacular}

O poder da mídia, as sutis técnicas de desinformação, o recurso maciço à publicidade tornam cada dia mais necessária uma reflexão sobre as condições de uma palavra argumentativa oposta à retórica e à manipulação. (BRETON, 2003, p. 21).

Ao analisar a realidade do neoliberalismo no Brasil, é possível perceber que não existe exatamente um marco teórico definido, por outro lado, o neoliberalismo apresenta-se aqui mais como um conjunto de regras práticas, o que corrobora para a difícil identificação de políticas neoliberais no âmbito das políticas sociais. Ao passo que, a análise calculista responsável por medir a relação custo/ganho e, como essa levará ao lucro, ampliou as contradições da dominação capitalista. O lucro também adquire novas formas para além do dinheiro, isto é, o conhecimento torna-se mercadoria, assim como o tempo e as instituições.

2 "Insisto sobre a importância do capital-imperialismo com a pretensão de sublinhar que não se trata apenas de uma 'política', mas de uma totalidade que somente pode existir em processo permanente de expansão, e que, tendo ultrapassado um determinado patamar de concentração, se converte em forma de extração de mais-valor dentro e fora de fronteiras nacionais" (FONTES, 2010, p. 152). 
Nesse sentido, a difusão da lógica do capital a todas as relações sociais provocou uma verdadeira mudança de paradigma, onde o trabalhador, sob contrato, está cada vez mais inserido em um Estado de lógicas corporativistas e, portanto, as assimila e é a todo tempo conformado pela nova dinâmica.

Ora, como podemos chamar "democrático" um Estado neoliberal? Se, é sabido que, dentro de seus moldes e escassas possibilidades, é sobretudo um Estado policial, coercitivo e repressivo $^{3}$. À vista disso, a lógica neoliberal comporta hoje, em uma sociedade de classes extremamente aprofundadas, um cenário fantasioso-espetacular ${ }^{4}$, capaz de distrair a todo o momento do real aspecto político no qual o Brasil está inserido.

Guy Debord debruça-se sobre o tema do Espetáculo e seus desdobramentos em uma sociedade aprisionada, onde as relações sociais são mediadas por imagens e, assim, narra um ambiente onde a dominação de classe desenvolve meios cada vez mais instrumentais de imposição econômica. Nas palavras de Debord: "O espetáculo domina os homens vivos quando a economia já os dominou totalmente'” (DEBORD, 1967, p. 17).

Nessa acepção, existem muitos momentos em que a retórica da corrupção foi utilizada para despolitizar o debate social, dentre eles, é possível destacar o golpe de 64 no Brasil, onde os militares se afirmaram enquanto força política sustentando um discurso essencialmente contrário à subversão e à corrupção.

A retórica da corrupção perpassa muitos momentos da história brasileira e, pode ser resgatada a qualquer tempo, principalmente em momentos críticos do conflito social. Como sinaliza Marx ao afirmar que os grandes fatos da história mundial são encenados duas vezes, a primeira vez como tragédia e a segunda como farsa (MARX, 2011).

Vale destacar ainda um ponto significativo: Durante o período ditatorial, posicionamentos contrários ao regime militar, que escapassem da discussão de corrupção da pequena política e expusessem, por exemplo, a forma intrínseca da corrupção ao capitalismo estaria fundamentalmente "contra a pátria",5.

3 “Em um país como o Brasil, o pano de fundo da 'militarização da questão urbana' são sentimentos difusos e cada vez mais presentes de medo e insegurança, reverberados e retroalimentados pela mídia (afinal, o horror quotidiano rende boas manchetes) e pelo sistema político-eleitoral (afinal, o medo generalizado costuma ser um bom instrumento de controle sócio-espacial)'” (SOUZA, 2016, p. 13).

${ }^{4}$ A ideia de "'fantasia", aqui, parte da análise de Zizek ao que denomina fantasia ideológica: "A ilusão, portanto, é dupla: consiste em passar por cima da ilusão que estrutura nossa relação real e efetiva com a realidade. E essa ilusão desconsiderada e inconsciente é o que se pode chamar de fantasia ideológica" (RECH, 2013, p. 122 apud ZIZEK, 1996, p. 316).

${ }^{5}$ Retórica do medo adotada pelos regimes militares. No Brasil, o lema "Brasil, ame-o ou deixe-o", ganhou forte expressão na sociedade. 
O acúmulo histórico de todas as experiências marcadamente coercitivas configura, da mesma forma, um acúmulo de predicação e manifestação da linguagem, sob bases retóricas direcionadas a abrandar determinados conflitos sociais. Como argumenta Gramsci:

Se é verdade que toda linguagem contém os elementos de uma concepção do mundo e de uma cultura, será igualmente verdade que, a partir da linguagem de cada um, é possível julgar da maior ou menor complexidade da sua concepção de mundo. (GRAMSCI, 1995, p. 13).

As condições materiais, tão logo, determinam as condições de reprodução da intelectualidade - no sentido ampliado de Gramsci - e, por consequência, a formação da cultura nacional. Construção essa que pressupõe supremacia ${ }^{6}$, para que se estabeleçam as circunstâncias de sua disseminação.

Nessa perspectiva, historicamente, no Brasil, a retórica da corrupção foi utilizada para despolitizar e reduzir os grandes debates a pequenos momentos pontuais da vida política, protagonizados em sua maioria pela cena parlamentar e personalista. Associando, frequentemente, a política à imagens caricaturais de vícios e desvios.

Não raro, a incrível difusão de informação e os avanços tecnológicos imprimem uma falsa ideia de desenvolvimento e progresso, quando na verdade significam, em larga medida, mecanismos de controle e distração. Em suma, há uma maior passividade ao mundo ${ }^{7}$.

De modo que, no que se refere à realidade brasileira,é possível notar a presente e recorrente ideia de uma "crise" ideológica, política e partidária,ou ainda a ideia de como as instituições democrático-burguesas estão passando por crises decorrentes de uma outra crise, uma crise principal, a Crise do $\mathrm{Capital}^{8}$. Ao passo que, nascem neste terreno discursivo, uma infinidade de análises economicistas e de um determinismo brutal. Conforme observa Gramsci: "quando a concepção de mundo não é crítica e coerente, mas ocasional e desagregada, pertencemos simultaneamente, a uma multiplicidade de homens-massa", (GRAMSCI, 1995, p. 12).

Estabelecer e estimular a retórica da corrupção como a causa das problemáticas sociais e políticas é desviar, de igual modo, a atenção para o aspecto mais germinal das problemáticas - às grandes questões, no seio da grande política. De tal modo que, ao fazê-lo, o que se constitui é um real conformismo, corroborando cada vez mais para discursos que se alinham a

6 "O termo supremacia designa o momento sintético que unifica (sem homogeneizar) a hegemonia e a dominação, o consenso e a coerção, a direção e a ditadura” (COUTINHO, 1999, p. 130).

${ }^{7}$ Essa passividade está presente de igual forma na esquerda, ao adotar a postura de tão somente reação e abrir mão, dessa maneira, do agir político.

${ }^{8} \mathrm{Se}$, por um lado, a cena política e o quarto poder alertam a todo tempo sobre a crise do Capital, por outro lado, e de forma concomitante, se evidencia outra crise: A crise do capitalismo. Ambas as crises têm como ponto de partida uma problemática em seus valores. Todavia, a crise do Capital se refere aos valores financeiros, enquanto que a crise do capitalismo se refere aos valores éticos e morais do Capitalismo. 
uma concepção de mundo de "interesses restritos, mais ou menos corporativos ou economicistas, não universais"' (GRAMSCI, 1995, p.13).

Ao dedicar-se ao estudo da argumentação e da linguagem, Philippe Breton sinaliza: "Argumentar, numa perspectiva literária, se reduz finalmente a uma apresentação estética que faz mais uso da sedução do belo do que do raciocínio rigoroso"' (BRETON, 2003, p. 15).

A retórica por parte dos economistas e determinados órgãos do governo é tão potente que, por vezes, consegue até mesmo confundir as forças de esquerda. Nesse cenário, discursos que sustentam as necessidades de resgatar a 'confiança"' do mercado, crescem cada vez mais e de forma tão exponencial que nem temos tempo para pensar lucidamente: " Mercado tem confiança?",

O mercado, nesse sentido, passa a receber aspectos subjetivos, como confiança e otimismo, que o conferem praticamente uma natureza humana. Não temos tempo para questionarmo-nos, porque de outro lado, recebemos uma enxurrada de informações que não nos permite refletir - e isso faz parte do projeto. Ora, na sociedade do espetáculo, os acontecimentos políticos e os escândalos de corrupção também são formas de entretenimento. Em síntese: "O espetáculo é o capital em tal grau de acumulação que se torna imagem", (DEBORD, 1967, p. 25).

Considerando que a inserção em um sistema de modo de produção capitalista pressupõe o aperfeiçoamento de seus elementos e reciclagem do próprio capital, ainda que se observe as crises recorrentes do capitalismo, a racionalidade neoliberal ${ }^{9}$ e a lógica do capital são estendidas a todas as relações sociais e a todas as esferas da vida cotidiana, isto é, como sustentado por Dardot e Laval: O neoliberalismo como racionalidade.

Não obstante, a perspectiva sobre o Estado-empresa e como a lógica neoliberal estimula a dinâmica cada vez mais privatizada no interior do Estado, fundamenta em grande medida a razão pela qual há marcadamente na sociedade um velado, e muitas vezes ostensivo, egoísmo social.Além disso, uma vez enraizado como uma verdadeira racionalidade, o neoliberalismo finca de modo objetivo e subjetivo a competitividade como forma de separação ideológica e prática. Segundo Dardot e Laval:

É essa nova concepção 'desencantada' da ação pública que leva a ver o Estado como uma empresa que se situa no mesmo plano das entidades privadas, um 'Estado-empresa' que tem um papel

9 "O neoliberalismo não se pergunta mais sobre que tipo de limite dar ao governo político, ao mercado (Adam Smith), aos direitos (John Locke) ou ao cálculo da utilidade (Jeremy Bentham), mas, sim, sobre como fazer do mercado tanto o princípio do governo dos homens como o do governo de si” (DARDOT; LAVAL, 2016, p. 34). 
reduzido em matéria de produção do 'interesse geral'. (DARDOT; LAVAL, 2016, p. 274).

O momento da autocracia burguesa de um Estado-empresa não apenas admite essa sociedade espetacular, como também precisa dela. De modo que, o que se observa no Brasil da atualidade é uma verdadeira simbiose entre espetáculo e pequena política.

À vista disso, enseja-se o debate entre a dicotomia público e privado nesse contexto. Assim, sob a ótica da retórica da corrupção, ataca-se constantemente o Estado e a coisa pública sem que se interpele as dinâmicas lucrativas dos grandes grupos econômicos, asseguradas por lei. Ou, em outras palavras, a privatização no interior do Estado:

A política de privatização é um elemento do modelo neoliberal que atinge de modo desigual os diferentes setores da burguesia. Ela tem, como indicamos, aumentado o patrimônio e os lucros do grande capital em detrimento do médio capital e ferido os interesses da camada burocrática que controlava essas grandes empresas estatais. (BOITO, 2007, p. 6).

Não se questiona, porém, por parte desses mesmos grupos que compõem a sociedade política e que se utilizam da retórica da corrupção, as chamadas "parcerias" entre o setor público e o setor privado. Onde, necessariamente, o Estado arca com os custos mais elevados e as empresas lucram cada vez mais, fortalecendo paulatinamente a concentração de renda e a acumulação de capital. Tampouco, nessa mesma perspectiva, se questiona a privatização no interior do Estado que, já sem o controle social real, incentiva licitações atrozes.

Nessa confusão entre jogo de poderes e interesses, perdemos o foco e a dimensão do real. Atentamo-nos ao esquema de influências e às figuras políticas e nos esquecemos das relações público- privadas, que determinam em larga medida a cena política.

De fato, um dos efeitos da nova gestão pública, é que os limites entre o setor público e o setor privado se embaralham. Aliás, a própria ideia de um setor público cujos princípios transgridem a lógica mercantil é posta em questão com a multiplicação das relações contratuais e delegações, bem como as transformações sofridas pelo emprego público no sentido de uma maior diversidade de formas e de uma precariedade mais desenvolvida. (DARDOT; LAVAL, 2011, p. 37).

O debate sobre as Parcerias Público Privadas ${ }^{10}$ é indispensável ao incidir sobre essa temática, ainda que não seja o foco do presente artigo. Ocorre que o sucateamento, a 
superlotação e a má administração dos espaços públicos contribuem para a argumentação política que dá sustento às PPP's ${ }^{11}$ e à gestão aparentemente eficiente da iniciativa privada. De igual modo, se reproduz a mesma lógica: Desmoralizar o que é oriundo da coisa pública e do Estado, para enaltecer as condutas privatizantes.

Ademais, existe hoje, no Brasil, um latente paradoxo que cumpriu o mérito de entreternos por quase um ano - entre a queda de um presidente e a ascensão de outro - e esse consiste em: Há uma disputa entre setores do bloco dominante, mas existe também consenso. O dissenso reside em quem tocará as reformas, mas não há dúvidas de que precisam ser feitas. Entre delações e prisões, vazamentos de áudio e novas atribuições do aparato jurídico, a sociedade civil perde de vista o aspecto real e, ao fazê-lo, entretém-se.

Vale ressaltar ainda que, as referidas reformas são postas como necessárias, justamente devido ao discurso de que as vicissitudes comprometedoras e intrinsecamente irregulares da máquina pública, carecem da iniciativa privada, por ser menos "aparelhada" e, portanto, mais eficaz no cumprimento de suas funções.

O que se percebe hoje é um capitalismo que se auto fortalece e se retroalimenta, que nos propõe um mundo agudamente fantasioso, onde o trabalhador não se vê mais como trabalhador. Consequência esta decorrente de um capital extremamente concentrado e flexibilizado, concentrado no sentido de propriedade e flexibilizado no que tange os direitos. Nesse sentido, a lógica-fantasia neoliberal, apoiada na espetacularização, apresenta um mundo "sem patrões" 12 ao aprofundar as complexidades de industrialização da área de serviços.

Na medida em que, todas essas novas concepções, como o da falsa autonomia ou da liberdade do ser social, e o ideário neoliberal enraízam-se no discurso corrente da sociedade civil, se estabelece uma relação de hegemonia ${ }^{13}$ (COUTINHO, 2010, p. 30).

Nesse contexto, o que ocorre, de maneira mais concreta, é a que a dinâmica patronal recebe um aspecto turvo, devido suas relações e articulações em rede, e sua prática em Holdings - equipes altamente concentradas do capital internacional.

É fundamental para a racionalidade neoliberal que nos mantenhamos dispersos, imersos em um mundo calculista, competitivo autocentrado e efêmero, de prazeres viciantes

\footnotetext{
11"Surge a parceria público-privada como novo incentivo ao ingresso de capitais privados no financiamento do setor de infraestrutura. A proposta da parceria público-privada é dinamizar alguns aspectos dessa lei que trata de forma mais genérica da concessão de serviços públicos"' (LIMA; COELHO, 2015, p. 2).

12 "Quanto mais se expande o capitalismo, mais o trabalho assume múltiplas configurações, recobertas por contraditórias aparências, disseminadas, enfatizadas pela propaganda e pela atuação empresarial e estatal", (FONTES, 2017, p. 47).

13 "A novidade introduzida por Gramsci não diz tanto respeito à questão da hegemonia, já abordada por Lenin, mas ao fato de que a hegemonia - enquanto figura social - recebe agora uma base material própria, um espaço autônomo e específico de manifestação"' (COUTINHO, 1999, p. 128).
} 
de um mundo 'perfeito' e pormenorizado no ideal, onde é forjado um eu que, a todo momento, se frustra. E, dessa maneira,em um cenário difuso e conturbado como este, as forças de esquerda se perdem em certa medida, quando são levadas a atender interesses imediatos. Assim, Gramsci define:

O desenvolvimento político do conceito de hegemonia representa além do progresso político-prático - um grande progresso filosófico, já que implica e supõe necessariamente uma unidade intelectual e uma ética adequadas a uma concepção do real que superou o senso comum e tornou-se crítica. (GRAMSCI, 1995, p. 21).

O que está no cerne da questão quando discutimos este momento de selvageria neoliberal, circunstanciado em terreno periférico, é que, pelo menos de modo aparente, a burguesia - detentora dos principais veículos de comunicação - está disposta a socializar, em pequena medida, o debate sobre o aspecto social, desde que não incida sobre o modo de produção capitalista e em seu arcabouço jurídico. Este é o limite do que é forjado como 'Democracia'" no Brasil e em outros países latino-americanos.

Posto isso, a apropriação de pautas sociais específicas garante, em certa medida, a manutenção ideológica de sua reprodução e, além disso, previne o desgaste com uma possível crise ideológica, a chamada crise do capitalismo.

Tendo em vista essa mínima socialização do debate, por parte da elite política e dos principais veículos de comunicação de massa, é possível observar um intenso esforço do capital em se reproduzir sem grandes empecilhos e, não à toa, é interessante para tanto, que se aproprie de algumas pautas universais de considerável expressão na sociedade.

Em outras palavras, não existe uma preocupação por parte do capital em reparar as sequelas de sua produção desenfreada. Contudo, é preciso atentar que, de outro modo, é fundamental que adote discursivamente determinadas pautas, para que seja possível manter-se ideologicamente.

Em uma realidade apressada como a que vivemos e com uma sociedade que fagocita informação enquanto é fagocitada pela repetição viciante e vacilante dessas mesmas informações, a compreensão do método dialético nunca foi tão necessária.

\section{Dialética da Grande e Pequena política}


Grande política (alta política) - pequena política (política do dia-a-dia, política parlamentar, de corredor, de intrigas). A grande política compreende as questões ligadas à fundação de novos Estados, à luta pela destruição, pela defesa, pela conservação de determinadas estruturas orgânicas econômico-sociais. A pequena política compreende as questões parciais e cotidianas que se apresentam no interior de uma estrutura já estabelecida em decorrência de lutas pela predominância entre as diversas frações de uma mesma classe política. Portanto, é grande política tentar excluir a grande política do âmbito interno da vida estatal e reduzir tudo à pequena política ${ }^{14}$. (GRAMSCI, 1991)

Antonio Gramsci é considerado um teórico da superestrutura e produz sua teoria em contribuição aos estudos de Marx, em um momento em que o fenômeno estatal - diante da realidade do capitalismo desenvolvido - enfrenta novos obstáculos e consequentemente novas contradições a serem superadas. É devido a este fato que Gramsci observa a ampliação da concepção de Estado como algo necessário para ilustrar esse novo momento, ou ainda, esse novo estágio do capitalismo, que Marx não vivenciou.

Gramsci parte da concepção de duas esferas principais: a sociedade política - a qual funciona através de mecanismos responsáveis por garantir o monopólio legal da repressão; e a sociedade civil que engloba as diferentes organizações difusoras de ideologia como Igrejas, partidos políticos e sindicatos.

Nesse sentido, a relativa autonomia dessas duas esferas reside no fato de exercerem funções diferentes ${ }^{15}$. Contudo, o que deve se considerar é que ambas cumprem função de conservar uma base econômica na sociedade civil, onde as classes procuram exercer sua hegemonia e ganhar aliados (COUTINHO, 1999).

A fim de melhor contextualizar, é necessário pontuar aqui o que significa, de maneira prática, a ideia ampliada de intelectual proposta por Gramsci, sem que exista o intuito de fugir da proposta desse artigo de analisar a corrupção como retórica, mas, levando em consideração que a abordagem é de relevante importância, uma vez que a ideia de intelectual condensa, dentre outros temas, as noções de senso-comum e consenso.

Ao referir-se aos intelectuais no sentido ampliado, Gramsci não ignora o senso comum. Ao contrário disso, compreende que qualquer um que exerça a atividade intelectual, independentemente de seu grau, é fundamental para hegemonizar discursivamente

${ }^{14}$ Grifo nosso.

15 "No âmbito e através da sociedade civil, as classes buscam exercer sua hegemonia, ou seja, buscam ganhar aliados para suas posições mediante a direção política e consenso; por meio da sociedade política, ao contrário, as classes exercem sempre uma ditadura, ou mais precisamente, uma dominação mediante a coerção", (COUTINHO, 1999, p. 128). 
determinado processo histórico. Nas palavras do autor: "significa que, se pudesse falar de intelectuais, é impossível falar de não-intelectuais, porque não existem não-intelectuais", (GRAMSCI, 1995, p. 7).

Nessa mesma perspectiva de poder material e intelectualidade ampliada, Gramsci denota: "A classe que dispõe dos meios de produção material dispõe também dos meios de produção intelectual, de tal modo que o pensamento daqueles aos quais são negados os meios de produção intelectual está submetido também à classe dominante.' (GRAMSCI, 2002, p.112 apud MOTTA, 2012).

É principalmente a partir desse entendimento do fazer e ganhar aliados que a retórica despolitizante da corrupção não é, portanto, um fim em si mesma. Ao contrário disso, busca acentuar cada vez mais os discursos reacionários no senso comum ${ }^{16}$ e, à medida que o faz, arquiteta a sua hegemonia mercadológica.

Por conseguinte, é possível notar que há certo descompasso entre indivíduos - sujeitos sociais - e o tempo histórico, de maneira que se torna frequente o discurso corrente de amplificar os acontecimentos vivenciados pelo próprio narrador.

Em síntese, é corriqueiro perceber que os indivíduos tendem a exaltar seu próprio tempo. Uma concretude disso é a própria percepção da elite política e econômica em sugerir, constantemente, que o Brasil vivenciou o maior escândalo de corrupção da história nacional entre 2014 e 2018 com a Operação Lava-Jato. O que, evidentemente, não é um fato. Isso porque, para além de uma crítica mais radical de que a corrupção é germinal do próprio capitalismo, a história brasileira conta com vastos esquemas de corrupção. O exemplo historicamente mais recente é o próprio período ditatorial. Em suma: Esse descompasso entre o tempo de vida de um indivíduo e o tempo em que a história se faz, implica em retóricas muitas vezes arriscadas. O indivíduo vê micro, a história vê macro.

Isto posto, é precisamente o constante e incansável esforço objetivo da grande mídia em subjetivar e moldar um pensamento hegemônico que contribui para a crescente retórica da corrupção como uma verdadeira chave da pequena política. Isso se traduz, de maneira prática, nas concepções de Estado e classe política que o senso comum e os intelectuais - no sentido ampliado - defendem de forma categórica. E, por consequência, na sua concepção das relações entre público e privado.

16 "Não existe um único senso comum, pois, também ele é um produto e um devenir histórico. A filosofia é a crítica e a superação da religião e do senso comum e, neste sentido, coincide com o 'bom senso' que se contrapõe ao senso comum'" (GRAMSCI, 1995, p. 14). 
Considerando, portanto, a ideia de que a retórica da corrupção, ao pungir abstrações e deturpações no terreno da política, possui rigorosamente uma função real e concreta, é possível apreender a fundamentalidade da construção da imagem para que se produza uma subjetividade convencida e devidamente entretida.

Escapando de anacronismos, a retórica da corrupção embasa importantes momentos históricos da política brasileira e, menos especificamente, da América Latina. De forma que, essa expressão garante, sobretudo, a pulverização da ofensiva neoliberal à concepção de Estado e espaço público. Ao alimentar o discurso e o sentimento da antipolítica no senso comum, se desestimula, consequentemente, o fazer política ${ }^{17}$, minando paulatinamente a possibilidade de sujeitos coletivos se organizarem em movimentos contra hegemônicos.

\section{Neoliberalismo: Consenso ou política de choque}

Economicamente, o neoliberalismo fracassou, não conseguindo nenhuma revitalização básica do capitalismo avançado. Socialmente, ao contrário, o neoliberalismo conseguiu muitos dos seus objetivos, criando sociedades marcadamente mais desiguais, embora não tão desestatizadas como queria. Política e ideologicamente, todavia, o neoliberalismo alcançou êxito num grau com o qual seus fundadores provavelmente jamais sonham, disseminando a simples ideia de que não há alternativas para os seus princípios, que todos, seja confessando ou negando, têm de adaptar-se a suas normas. ${ }^{18}$ (ANDERSON, 1995, p. 12).

Tendo em vista a acepção de Gramsci sobre pequena política e grande política, é possível notar que, ao afirmar que reduzir tudo à pequena política, atua-se na verdade no campo da grande política, Gramsci elucida para a total ausência de uma suposta "ingenuidade" da sociedade política ao realizar determinado esforço para incidir sobre a construção do consenso da sociedade civil. Expressando, assim, uma verdadeira "consciência"' do capital em propagar sua hegemonia no campo da cultura. A construção desse consenso, portanto,faz parte de um real projeto.

Desconsidera-se, dessa forma, as determinações mais amplas e instrumentais do processo político e social como, por exemplo, a clássica proposição da teoria marxiana que

17 “O critério central para a resolução da crise é a iniciativa dos sujeitos políticos coletivos, a capacidade de fazer política, de envolver grandes massas na solução de seus próprios problemas, de lutar cotidianamente pela conquista de espaços e posições" (COUTINHO, 1999, p. 155).

${ }^{18}$ Grifo nosso. 
evidencia a profunda desigualdade na reprodução das condições de produção, isto é: o atraso das relações de produção e o avanço das forças produtivas ${ }^{19}$.

Conforme analisa Coutinho: "Do ponto de vista ideológico, essa postura se manifesta, entre outras coisas, precisamente na tentativa teórico-prática de 'despolitizar' a sociedade civil" (COUTINHO, 2000, p. 21).

O esforço em disseminar-se ideologicamente, nesse contexto, está diretamente relacionado ao campo da linguagem e da repetição. Tão logo, partindo da ideia de que o significante sugere um fonema, um som, e o significado, de outro modo, aponta para a semântica da própria ideia, é possível inferir que existe uma dicotomia entre o significante da retórica da corrupção e seu respectivo significado. Ao passo que, o significante seria o da própria repetição incansável que marca a corrupção como a raiz de nossas deficiências políticas e econômicas. Por outro lado, o significado seria a consciência verbalizada da necessidade de hegemonizar-se. À esta mesma análise, aplica-se a lógica da grande política e pequena política.

Nesse sentido, é possível notar que o Estado se adequa ao capitalismo conforme suas necessidades, significa dizer que, com o advento das propostas neoliberais a ideia de mínimo social ou de solidariedade social também se adequou às mudanças do padrão de gestão econômica e produtiva. Dessa maneira, para discutir Estado brasileiro, é necessário enfrentar o padrão de acumulação capitalista e atentar para a realidade latente de interesses empresariais no campo do social, os quais, muitas vezes, se utilizam da retórica simplista e despolitizante da corrupção para garantir sua reprodução econômica.

O ponto fundamental está na condição das relações de produção garantidas pelo poder estatal nos aparelhos de estado que, em última instância, refletem relações de exploração. Nessa perspectiva, associar a corrupção à máquina pública faz parte de uma construção retórica de convencimento sem que exista, a priori, um compromisso com a verdade dos fatos $^{20}$. O primordial, aqui, é a construção de consenso.

Seria possivel também justificar o fato de que os interessados em que a crise se resolva de seu próprio ponto de vista finjam acreditar e proclamem em voz alta que se trata da 'corrupção' e da 'dissolução' de uma série de 'principios ${ }^{21}$ (imortais ou não): Cada um é o melhor

${ }^{19}$ Ou seja, se por um lado há um desenvolvimento cada vez maior das capacidades tecnológicas e, portanto, uma dinamização do trabalho, de outro, é possível observar a precarização, por exemplo, do transporte público e do próprio trabalho.

20 "A retórica se preocupa muito mais com a adesão do que com a verdade, por isso utiliza-se da linguagem comum do dia-a-dia, e não de uma linguagem técnica ou especializada"' (TREIN, 2005).

${ }^{21}$ Grifo nosso. 
juiz na escolha das armas ideológicas mais apropriadas ao fim de que pretende alcançar, e a demagogia pode ser considerada uma excelente arma. (GRAMSCI, 2000, p. 96).

Verifica-se, porém, que, a linha que separa uma declarada ditadura de uma "democracia"- que atua sob condições de um Estado-empresa, intensamente coercitivo, e que atende à demandas sinuosas de um capital extremamente concentrado no sentido da propriedade - é extraordinariamente tênue. O que é crucial, em qualquer um dos regimes, é a construção de consenso. Para melhor elucidar esta ideia: ''O fato de que um Estado seja mais hegemônica-consensual e menos 'ditatorial' ou vice-versa, depende da autonomia relativa das esferas superestruturais" (COUTINHO, 1999, p. 131). Existem, dessa maneira, segundo a teoria gramsciana, dois tipos de consenso: O consenso ativo e o consenso passivo. À vista disso, o que se entende por pequena política, é propriamente relacionado ao consenso passivo $^{22}$.

Tendo em vista a ideia de consenso proposta por Gramsci, David Harvey faz uma importante consideração a respeito do contexto do que ele chama, "neoliberalização":

Nenhum modo de pensamento se torna dominante sem propor um aparato conceitual que mobilize nossas sensações e nossos instintos, nossos valores e nossos desejos, assim como as possibilidades inerentes ao mundo social que habitamos. Se bem sucedido, esse aparato conceitual se incorpora a tal ponto ao senso-comum que passa a ser tido por certo e livre de questionamentos ${ }^{23}$ (HARVEY, 2008).

Nesse sentindo, ao fertilizar o terreno neoliberal e disseminar a cultura do empreendedorismo e do individualismo, se enfraquece, por um processo dialético, a ação política do que se é coletivo e questionador aos moldes neoliberais. O que se observa, nessa acepção, é a total e completa dependência entre o próprio espetáculo e a sociedade civil.

Para exemplificar melhor este momento do que chamo "fertilização" do terreno neoliberal, é possível considerar as recorrentes medidas objetivas e subjetivas da ex-primeiraministra da Inglaterra, Margaret Thatcher. Sobre ela, Harvey pontua:

O melhor que ela pôde fazer foi tentar implantar à força uma cultura do empreendedorismo [...] A primeira-ministra forjou $o$

22 '"Esse tipo de consenso não se expressa pela auto-organização, pela participação ativa das massas por meio de partidos e outros organismos da sociedade civil, mas simplesmente pela aceitação resignada do existente como algo "natural"' (COUTINHO, 2010, p. 31).

${ }^{23}$ Grifo nosso. 
consentimento $^{24}$ mediante o cultivo de uma classe média que adorava os prazeres da casa própria, da propriedade privada em geral, do individualismo e da liberação de oportunidades de empreendimento. (HARVEY, 2008).

Tendo em vista o trecho supracitado, é possível notar o controle estabelecido pelo neoliberalismo e sua respectiva capacidade de se retroalimentar. Uma vez arraigado na sociedade civil, não existe mais a necessidade de um grande esforço para construir o consenso e garantir sua solidez. Ao contrário, o que se mostra necessário, algumas décadas após ao processo de neoliberalização, é tão somente a estruturação de novos mecanismos e estratégias que assegurem sua hegemonia enquanto sistema.

Não raro, uma dessas estratégias e tema deste estudo, é a própria espetacularização da pequena política, através da retórica da corrupção. Ora, este esforço por parte do Capital em afastar os sujeitos dos temas da grande política, ao espetacularizar a pequena política, é a verdadeira manifestação dialética do que se considera como grande política.

O ponto de inflexão, aqui, reside no movimento pendular que o neoliberalismo assume na história, ora inclinando-se para a construção de consenso, ora determinando o choque ${ }^{25}$ como política e doutrina.

Há, no entanto, a necessidade de pontuar aqui uma importante questão: O neoliberalismo se disseminou em tal escala material, linguística e ideológica, que o próprio consenso não é mais, de fato, uma preocupação por parte do Capital. Partimos aqui da ideia de que a espetacularização da pequena política é indício real de uma permanência da política, mas agora, de uma política de choque ${ }^{26}$. Pois, o consenso, ainda que situado de forma contrária à política e à coisa pública, aparece dessa maneira como uma forma de revelar que a política se preserva.

\section{Conclusão}

Existe uma notável dedicação, por parte do patronato e da maioria da classe política, em incentivar gradativamente a antipolítica e alimentar a imagem de que o ambiente político é uma zona de balbúrdia, sem perspectiva para o social e de condutas desviantes. Isso, é sobretudo, uma abstração. Isso porque, o que determina hegemonicamente as tomadas de

\footnotetext{
${ }^{24}$ Grifo nosso.

${ }^{25}$ Em alusão a Doutrina do choque de Naomi Klein: “A versão extraordinariamente violenta de capitalismo de desastre, que se tornou dominante depois do 11 de Setembro, surgiu, em parte, porque os choques mais brandos Crise da dívida, colapsos monetários, ameaça de ficar para trás 'na história' - já estavam perdendo sua potência, em grande medida por excesso de uso''(KLEIN, 2007, p. 545).
} 
decisão e as determinações - arbitrárias ou não - de uma maioria parlamentar é, exatamente, a relação estabelecida entre os aparelhos privados de hegemonia ${ }^{27}$ - em constante busca por consentimento - e o próprio Estado. E é esta a dimensão que não se deve perder de vista, apesar de todo esforço da grande mídia em fomentar a retórica da corrupção personalista e partidária.

À vista desse estudo, cabe ainda pontuar o caráter disciplinador do Capital ao dedicarse no fomento dos discursos sobre empreendedorismo, cunhado em um ideal de sujeito autônomo e independente dos vínculos entre patrão e empregado. Aqui, assim como em outros momentos, a referida disciplina se impõe no campo da cultura. É fundamental, nesse sentido, munir os sujeitos de uma ideologia que acredita ser "'desideologizada" ${ }^{28}$, ao mesmo tempo em que reforçam a ideia da antipolítica ${ }^{29} \mathrm{e}$ de um darwinismo social ${ }^{30}$ brutal.

Universalizar, portanto, o discurso neoliberal e a cultura de um forte egoísmo social, é criar condições ideológicas para a disseminação de temas despolitizantes, como o da própria retórica da corrupção.

Sobre este terreno analítico, Bianchi defende a ideia de que "para travar a batalha no campo da cultura de modo eficiente é preciso recolocar a estratégia em seu lugar e passar para o terreno da grande política' (BIANCHI, 2016, p. 124). Nessa acepção, ao não se restringir à pequena política e seus vícios cotidianos, a discussão ganha uma maior profundidade e tangibilidade discursiva, e evidencia expressamente o que há de mais visceral nas relações de poder.

Nessa perspectiva, a construção do consenso é elemento cristalizador para hegemonizar o espetáculo da corrupção na pequena política. Nessa análise, as retóricas que buscam convencimento e consenso, como a retórica da Corrupção, estão sempre acompanhadas de muitos discursos hegemônicos e disciplinadores, que buscam orientar a sociedade para uma opinião comum.

Sem dúvida, há um certo dinamismo que incide sobre a experiência prática e a experiência subjetiva, onde os conceitos - como os de liberdade e justiça social - são compreendidos sob diferentes chaves e perspectivas. Nesse sentido, a busca por consenso e o amadurecimento argumentativo das retóricas que buscam despolitizar o campo da cultura, se

${ }^{27}$ Compreende-se: "Organismos sociais coletivos voluntários e relativamente autônomos em face da sociedade política.” (Coutinho, 1999). Ou ainda, a mídia, a família e as principais organizações sociais.

28 "Em lugar de ideologia, os neoliberais têm conceitos. [...] Precisamos de parcerias, não de governo forte. Falem de necessidades nacionais, não de demandas de interesses especiais. Exijam crescimento, não distribuição. Acima de tudo, tratem do futuro. Repudiem o passado"' (SCHNEIDER, 1989 apud DRAIBE, 1993).

29 "Também contribuem para difundir essa hegemonia da pequena política todos os que dizem que vivemos o fim das ideologias, que a diferença entre esquerda e direita desapareceu', (COUTINHO, 2010, p. 31).

${ }^{30} \mathrm{Ou}$ o que se compreende como meritocracia. 
realiza não apenas de maneira discursiva no terreno político, tendo em vista que a retórica é um instrumento político, mas sobretudo de maneira explícita como é o quadroda política de choque, como a mais forte expressão da hostilidade do sistema neoliberal desenfreado.

A consagração de uma verdadeira e ostensiva política de choque significa que até certo ponto, a construção do consenso prosperou e atingiu seus objetivos materiais de reprodução. De outro modo, a política de choque não poderia se realizar de maneira tão efetiva.

Por fim, temos que o movimento por consenso ou choque é irregular,devido às circunstâncias ${ }^{31}$ que o neoliberalismo assume através do tempo, ao passo que, a história não deve ser apreendida sob retóricas simplistas e forjadas discursivamente. O risco desta apreensão reside na interdição de nosso agir e pensar lúcido. É necessário, portanto, contrahegemonizar o debate para que não percamos o aspecto real da política, da cultura e de nossa solidez enquanto sujeitos. E, uma vez cônscios, protagonizar nossa própria história

\section{REFERÊNCIAS}

ANDERSON, Perry. Balanço do neoliberalismo. In: SADER, Emir (Org.). Pósneoliberalismo: as políticas sociais e o Estado democrático. Rio de Janeiro: Paz e Terra,1995.

BIANCHI, Álvaro. A guerra que estamos perdendo. Rio de Janeiro: Mauad, 2016.

BOITO, Armando. Estado e burguesia no capitalismo neoliberal. Rev. Sociol. Polít., Curitiba, 28, p. 57-73, jun., 2007.

BRETON, Philippe. A argumentação na comunicação. Lisboa: Publicações D. Quixote, 1998.

COUTINHO, Carlos Nelson. Hegemonia às avessas: economia, política e cultura na era da servidão financeira. Rio de Janeiro: Boitempo, 2010.

BRASIL. Lei número 11.079, de 30 de Dezembro de 2004. Disponível em: <www.planalto.gov.br>. Acesso em: 29 maio 2018.

COUTINHO, Carlos Nelson. Gramsci: um estudo sobre seu pensamento político. Rio de Janeiro: Civilização Brasileira, 1999.

31 “Os homens fazem a sua própria história: contudo, não a fazem de livre e espontânea vontade, pois não são eles quem escolhem as circunstâncias sob as quais ela é feita, mas estas lhes foram transmitidas assim como encontraram. A tradição de todas as gerações passadas é como um pesadelo que comprime o cérebro dos vivos" (MARX, 2011). 
COUTINHO, Carlos Nelson. La societàcivile in Gramsci e ilBresiledioggi. In:

RELAZIONEPRESENTATAALLÁ IL CONFERÊNCIA INTERNACIONAL DE ESTUDIOS GRAMSCIANOS. Puebla: UAP, 2000.

DARDOT, Pierre.; LAVAL, Christian. A nova razão do mundo: ensaio sobre a sociedade neoliberal. São Paulo: Boitempo, 2016.

DEBORD, Guy.A sociedade do espetáculo. Rio de Janeiro: Contraponto, 1997.

DRAIBE, Sonia. As políticas sociais e o neoliberalismo. São Paulo: Revista USP, 1993.

FONTES, Virgínia. O Brasil e o capital-imperialismo: teoria e história. Rio de Janeiro: EPSJV/ Editora UFRJ, 2010.

FONTES, Virgínia. Capitalismo em tempos de uberização: do emprego ao trabalho. Marx e o Marxismo v.5, n.8, jan/jun 2017.

GRAMSCI, Antonio. Cadernos do cárcere, v. III. Rio de Janeiro: Civilização Brasileira, 2000.

GRAMSCI, Antonio. Concepção dialética da história. Rio de Janeiro: Civilização Brasileira, 1995.

GRAMSCI, Antonio. Maquiavel, a política e o Estado Moderno. Rio de Janeiro: Civilização Brasileira, 1991.

GRAMSCI, Antonio. Os intelectuais e a organização da cultura. Rio de Janeiro: Civilização Brasileira, 1995.

HARVEY, David. O Neoliberalismo: História e Implicações. São Paulo, Edições Loyola, 2008.

KLEIN, Naomi. Choque: a ascensão do capitalismo de desastre. Rio de Janeiro, Editora Nova Fronteira S.A, 2007.

LIMA, Carlos Marcio Campos.; COELHO, Antonio Carlos. Alocação e mitigação dos riscos em parcerias público-privadas no Brasil. Rio de Janeiro: Revista de Adm. Pública, Rio de Janeiro, v. 49, n. 2, p. 267-291, mar./abr., 2015. DOI: 10.1590/0034-7612130020.

MARX, Karl. O 18 de brumário de Luís Bonaparte. São Paulo: Boitempo, 2011.

MOTTA, Vânia. Ideologia do capital social. Rio de Janeiro: eduerj, 2012. 
RECH, Hildemar. Slavoj Zizek: Real, Fantasia, Objetos sublimes da Ideologia, ato político e educação. São Paulo: Revista Dialectus, Ano 1 n.2, 2013.

SOUZA, Marcelo Lopes. Apresentação. Cidades Sitiadas. São Paulo: Boitempo, 2016.

TREIN, Sérgio Roberto. A retórica da corrupção: os neologismos propagandísticos utilizados para denunciar a corrupção no Governo Lula, em 2005. Bocc: 2006.

\section{Como referenciar este artigo}

FERREIRA, Fernanda Abi Chahin de Oliveira. A retórica despolitizante da corrupção e a dialética da grande e pequena política: uma narrativa sobre o espetáculo neoliberal. Rev. Sem Aspas, Araraquara, v. 7, n. 1, p. 49-67, jan./jun., 2018. ISSN: 2358-4238. DOI: 10.29373/semaspas.unesp.v7.n1.jan/jun.2018.11850

Submetido em: 10/10/2018

Aprovado em: 14/11/2018 